\title{
Effect of Ovarian Status on Oocyte Quality and Recovery Rate Retrieved by Aspiration Method in Buffalo Ovaries
}

\author{
Kolipaka Rajesh $^{1 *}$, B. Swathi ${ }^{1}$, G. Aruna Kumari ${ }^{2}$ and M. Shanmugam ${ }^{3}$ \\ ${ }^{1}$ Department of Veterinary Physiology, College of Veterinary Science, \\ Hyderabad - 500 030, India \\ ${ }^{2}$ Department of Animal Reproduction, Gynaecology and Obstetrics, College of Veterinary \\ Science, Korutla-505 326, India \\ ${ }^{3}$ Department of Veterinary Physiology, DPR-ICAR Rajendranagar, ICAR-DPR, \\ Hyderabad - 500 030, India \\ *Corresponding author
}

A B S T R A C T

\begin{tabular}{|c|c|}
\hline Keywo & \multirow{4}{*}{$\begin{array}{l}\text { A study was taken up to know the effect of corpus luteum (CL) on the oocytes retrieval, } \\
\text { quality in buffalo ovaries. Ovaries were collected from apparent healthy slaughtered } \\
\text { buffalo during breeding season and categorized based on the presence (or) absence of CL. } \\
\text { The cumulus oocyte complexes (COCs) were aspirated aseptically from the follicles of }>6 \\
\text { mm diameter present on the surface of the ovary by using } 18 \mathrm{G} \text { needle attached to } 5 \mathrm{ml} \\
\text { disposable syringe containing } 2 \mathrm{ml} \text { of collection media. The oocytes were graded based on } \\
\text { the presence of the cumulus cells complex around the oocytes. The mean A grade ( } 3-5 \\
\text { cumulus cell layer) oocyte recovery rate per ovary was } 1.35 \text { from the ovaries with CL, } \\
\text { while those without CL were } 1.97 \text {, and the mean oocyte recovery rate per ovary was } 1.78 \text {. } \\
\text { In conclusion, an ovary without CL was found to be more suitable for harvesting higher } \\
\text { number and superior quality of COCs. }\end{array}$} \\
\hline & \\
\hline & \\
\hline & \\
\hline
\end{tabular}

\section{Introduction}

Buffaloes contribute about $60 \%$ of the total milk production of India. Buffaloes in India are spread over almost all parts of the country with varying population density, majority (72\%) being concentrated in the north and western states. According to the $19^{\text {th }}$ livestock census (2012), total buffalo population in India is 108.7 million (NDDB, 2015-16), ranking number one in the world with huge genetic diversity. Buffaloes are preferred over cattle in India, because of their distinctive qualities such as better feed conversion efficiency, more resistance to diseases and higher milk fat percentage than in cows (Banerjee, 1998). However, they suffer from many reproductive issues like delayed puberty, postpartum ovarian inactivity and seasonality which cause great economic loss to the farmer and are the main obstacles in rearing this species.

Low reproductive efficiency characterized by low conception rate and high embryonic mortality is a major problem in buffaloes. 
Therefore, there is an imminent need to utilize recent advances in the field of reproduction to overcome these problems.

Assisted reproductive techniques (ART) were helpful in producing offspring from valuable farm animals that were considered less fertile using standard breeding techniques. ART include artificial insemination, embryo transfer, In Vitro fertilization, embryo cryopreservation, sexing of semen and embryos, cloning, transgenic technology, stem cell technology, embryo-genomics, micro and nanotechnologies. The recent scientific developments in ART have made it possible to manipulate the reproductive processes in many ways to revolutionize world animal agriculture. Efforts have been made to enrich the knowledge about various recent assisted reproductive techniques which may be helpful for improving the current status of livestock reproduction (Chakravarthi and Sri Balaji, 2010; Verma et al., 2012 and Hansen, 2014).

In Vitro maturation is a method in which immature oocytes are retrieved from the ovary and are allowed to mature in the laboratory which is a crucial step for fertilization and subsequent embryonic development (Meirelles et al., 2004 and Dadarwal et al., 2015). However, IVM of buffalo oocytes obtained poor recovery of good quality immature oocytes (Palta and Chauhan, 1998). So, the present study was taken up to assess the number of oocytes recovered per ovary with CL and without CL recovered from abattoircollected buffalo ovaries.

\section{Materials and Methods}

\section{Chemicals and media}

All media, hormones and chemicals were sourced from Sigma Chemical Co., USA, and plastic ware was from Nunc, Denmark, HEPES buffered tissue culture medium 199 supplemented with 10\% PBS (Handling medium) was used for washing and handling of oocytes. Heparin (25 $\mathrm{IU} / \mathrm{ml})$ was additionally added to the handling medium for collection of oocytes. Bicarbonate buffered tissue culture medium 199 (TCM199B) supplemented with gentamicin $(50 \mu \mathrm{g} / \mathrm{ml})$ was used as control medium for maturation of oocytes. The media used for transport and washing of ovaries, collection, handling, and maturation of oocytes were supplemented with gentamicin $(50 \mu \mathrm{g} / \mathrm{ml})$ and filter sterilized $(0.22 \mu \mathrm{m})$ before use. Handling, collection, and maturation media were equilibrated with $5 \%$ carbon dioxide in air, in a humidified atmosphere at $38.5^{\circ} \mathrm{C}$ for at least $2 \mathrm{~h}$ before use.

\section{Ovaries collection and oocytes collection}

Collection and processing of ovaries for aspiration of cumulus oocyte complexes (COCs) were carried out as described by Shahid et al., (2014). The ovaries were washed with phosphate buffered saline (PBS P 4417, Sigma USA) and kept in sterile polythene sachets containing warm $\left(37^{\circ} \mathrm{C}\right)$ PBS. These sachets were transported to the laboratory within 1-2 $\mathrm{hr}$ after collection in a thermos flask containing warm water $\left(37^{\circ} \mathrm{C}\right)$. External surface of the each ovary was sterilized by rinsing once in $70 \%$ alcohol and thrice in D-PBS. The COCs were aspirated aseptically from the follicles of $>6 \mathrm{~mm}$ diameter present on the surface of the ovary by using $18 \mathrm{G}$ needle attached to $5 \mathrm{ml}$ disposable syringe containing $2 \mathrm{ml}$ of collection medium. The COCs having homogenous cytoplasm and surrounded by more than three layers of compact cumulus cells were considered as good quality oocytes.

\section{Statistical analysis}

Oocyte recovery rate was analysed by TwoSample t-Test by assuming Equal Variances 


\section{Results and Discussion}

The present study was carried out with a total number of 1371 ovaries that were collected from the local slaughter house in Hyderabad during January-April 2017, of which 1010 ovaries were without corpus luteum (CL) $(73.67 \%)$ and 361 ovaries were with CL (26.33\%). A total of 2400 good quality (those oocytes having more than three layers of cumulus cells) oocytes were recovered from the ovaries out of which 1909 oocytes were recovered from the ovaries without $\mathrm{CL}$ and 491 oocytes were recovered from the ovaries with CL. The oocyte recovery rate per ovary was 1.35 from the ovaries with $\mathrm{CL}$, while those without CL were 1.97 , and the mean oocyte recovery rate per ovary was 1.78 (Table 1).

In the present study, a total of 1371 ovaries were collected during the experimental period from which 2400 good quality oocytes were recovered with a mean of 1.78 oocytes per ovary. These results were in agreement with that reported by Das et al., 1996 and Samad et al., 1998, who reported mean recovery rates of 1.7 and 1.76 respectively in buffaloes. However, higher oocyte recovery rates 2.2, 2.65 and 3.12 in buffaloes were reported by Tasripoo and Kamonpatana (1997), Shahid et al., (2014) and Ruhil and Purohit (2016) respectively. On the contrary, lower mean oocyte recovery values in buffaloes were reported by Totey et al., (1992), Madan et al., (1994) and Singh et al., (2001) which are 0.7, 0.42 , and 0.54 respectively. The reasons for these differences could be due to the reproductive status of the donor animal from which the oocytes were recovered (Madan and Raina, 1984; Totey et al., 1992 and Mehmood et al., 2011), the season of recovery along with the recovery procedure adopted (Sharma and Loganathaswamy, 2007 and Mehmood et al., 2011), the geography, the number of ovaries processed and the method of selecting ovaries from the slaughter house (Sharma and Loganathaswamy, 2007).

Buffaloes are usually more sensitive to environmental changes when compared to other livestock owing to poor thermoregulation. The degree of seasonal variation (particularly ambient temperature and relative humidity) on the breeding efficiency of buffaloes is well pronounced (Mahmoud and El-Naby, 2013).

The collection of majority of ovaries was carried out during relatively hot season (March-April), and this may be the reason behind lower mean oocyte recovery rates achieved here, when compared to the higher recovery rates reported by other workers.

Table.1 Number of oocytes and oocyte recovery rate
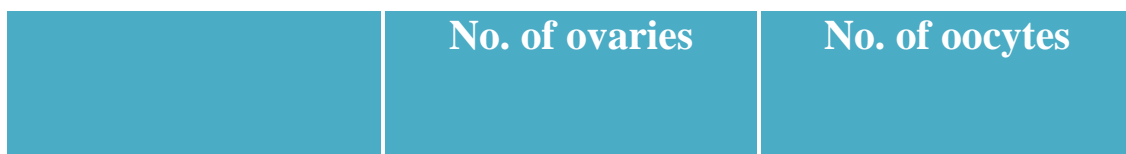

Oocyte recovery rate (per ovary)

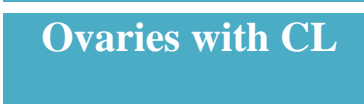

361

491

1.35
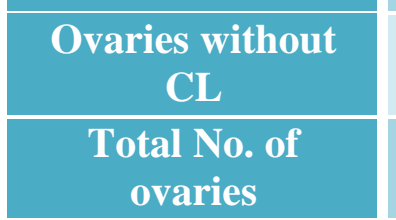

1010

1909

1.97

Total No. of

ovaries

(' $\mathrm{P}$ ' value at 48 degrees of freedom and 5\% level of significance is zero i.e., oocyte recovery rates of ovaries with $\mathrm{CL}$ and without $\mathrm{CL}$ differ significantly) 


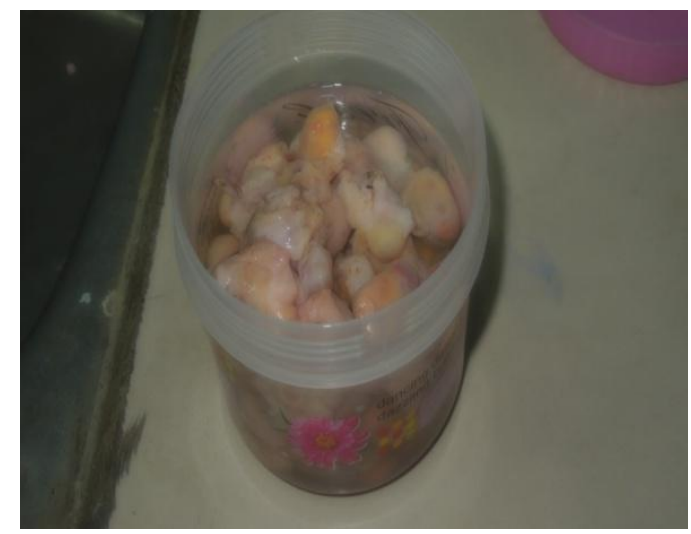

\section{Fig-A Collection of ovaries}

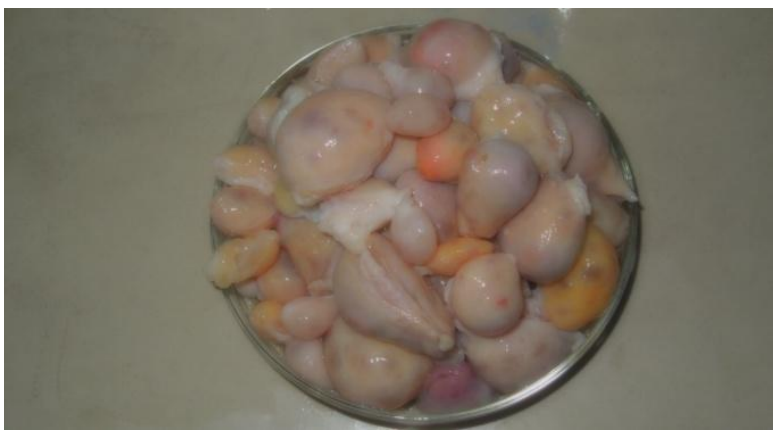

Fig-C Ovary with CL

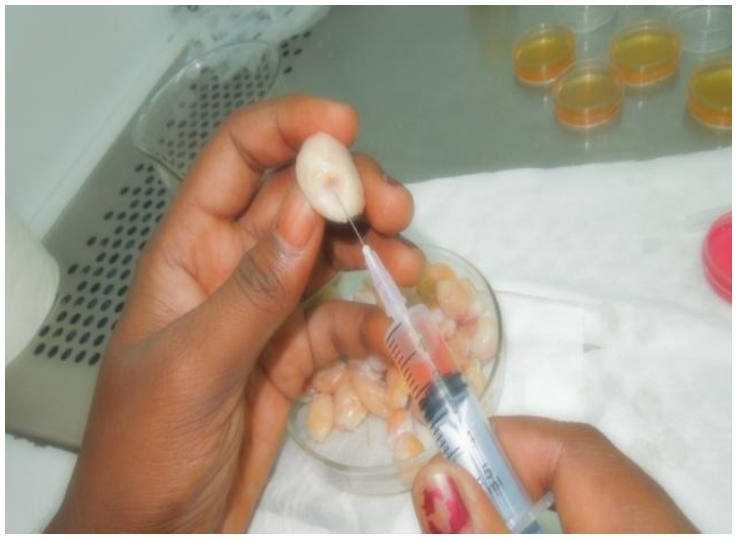

Fig-E Oocytes retrieved by Aspiration

\section{Method}

The mean oocyte recovery rate obtained from the ovaries with CL (1.35) was significantly $(\mathrm{P} \leq 0.05)$ lower than that obtained from the ovaries without CL (1.97). Similar trend was reported by Das et al., (1996) and Raza et al.,

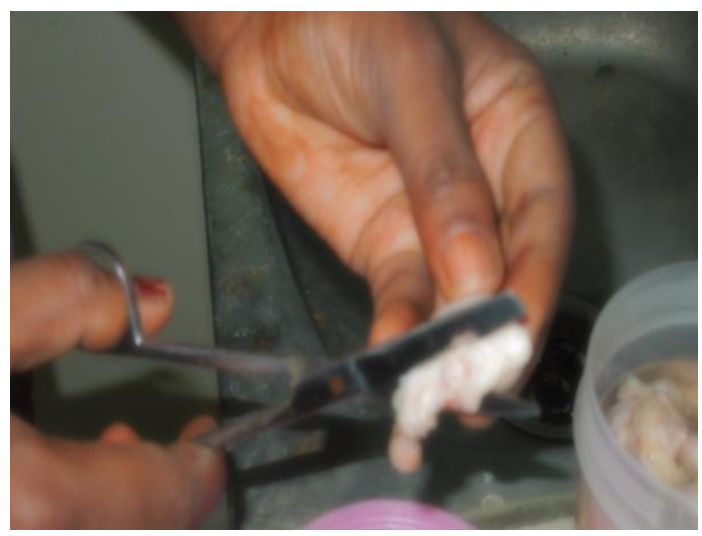

Fig-B Trimming of ovaries

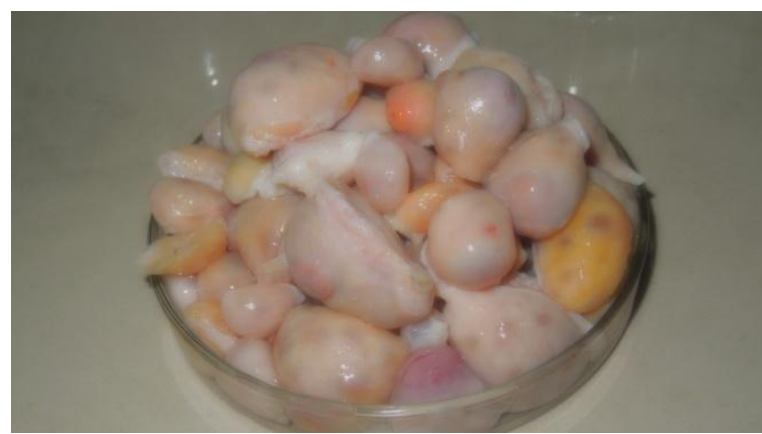

Fig-C Ovary without CL

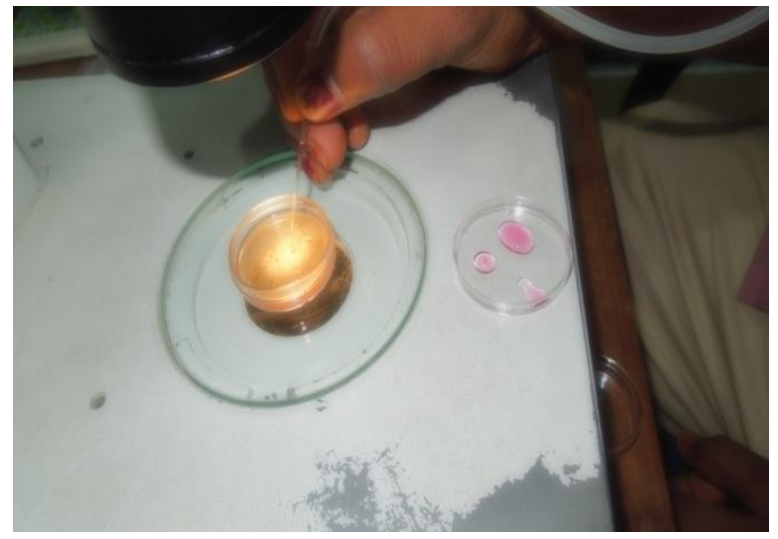

Fig- F Oocytes collected from Handling

\section{Medium}

(2001) recorded that the presence of a CL significantly reduces the number of ovarian follicles as well as the quality of oocytes in buffaloes. This is because follicular development is restricted, as lutein cells 
occupy most of the ovary (Kumar et al., 1997).

Oocytes can be retrieved by three methods viz. slicing, puncture and aspiration (Pawshe et al., 1994). Mehmood et al., (2011) and Shahid et al., (2014) reported that aspiration method is better than others for IVM studies as we can get developmentally competent oocytes from the follicles on the surface rather than from the cortex. Moreover, slicing method results in large amount of debris in the culture medium which adversely affects the IVM of buffalo oocytes (Shahid et al., 2014). Hence, aspiration method was chosen for oocyte recovery in the present study.

Only good quality oocytes (possessing more than 3 layers of granulosa cells) were chosen for In Vitro maturation in this experiment, as increase in the percentage of good quality oocytes increases the cumulus expansion and maturation rates. The oocyte quality is also determined by its ability to mature, get fertilized and give rise to normal offspring (Mahmoud and El-Naby, 2013).

\section{Acknowledgments}

Authors would like to acknowledge Department of Biotechnology (DBT), Government of India for provision of research grant (Proposal ID 12539) for carrying out out the present research work.

\section{References}

Banerjee, G. C., 1998. Text book of Animal husbandry, $8^{\text {th }}$ edition. Publisher Oxford and IBH publishing Co, Ltd New Delhi and Calcutta.

Chakravarthi, P. V., and Sri Balaji, N. 2010. Use of Assisted Reproductive Technologies for Livestock Development. Veterinary World. : 3 (5).
Dadarwal, D., Adams, G. P., Hyttel, P., Brogliatti, G. M., Caldwell, S. and Singh, J. 2015. Organelle reorganization in bovine oocytes during dominant follicle growth and regression. Reproductive Biology and Endocrinology. 13(1): 124.

Das, G. K., Jain, G. C., Solanki, V. S. and Tripathi, V. N. 1996. Efficacy of various collection methods for oocyte retrieval in buffalo. Theriogenology. 46(8): 1403-1411.

Gordon, I., 2003. Recovering the bovine oocyte. Laboratory Production of Cattle Embryos, Edition $2^{\text {nd }} \quad C A B$ International/Cambridge University Press, Cambridge: 97-112.

Hansen, P. J. 2014. Current and future assisted reproductive technologies for mammalian farm animals. In Current and future reproductive technologies and world food production: 1-22.

Kumar, A., Solanki, V. S., Jindal, S. K., Tripathi, V. N. and Jain, G. C. 1997. Oocyte retrieval and histological studies of follicular population in buffalo ovaries. Animal reproduction science. 47(3): 189-195.

Madan, M. L. and Raina, V. S. 1984. Fertility performance of buffalo under tropical conditions. Proc 10th Internat Cong on Anita Reprod and AI. Illinois: 142145.

Madan, M. L., Singla, S. K., Chauhan, M. B. and Manik, R. S. 1994. In Vitro production and transfer of embryos in buffaloes. Theriogenology. 41(1): 139143.

Mahmoud, K. G. M. and El-Naby, A. H. H. 2013. Factors affecting buffalo oocyte maturation. Global Vet. 11: 497-510.

Mehmood A, Anwar M, Andrabi S M H, Afzal $M$ and Naqvi S M S 2011. In Vitro maturation and fertilization of buffalo oocytes: the effect of recovery and maturation methods. Turkish 
Journal of Veterinary and Animal Sciences, 35(6): 381-386.

Meirelles, F. V., Caetano, A. R., Watanabe, Y. F., Ripamonte, P., Carambula, S. F., Merighe, G. K. and Garcia, S. M. 2004. Genome activation and developmental block in bovine embryos. Animal Reproduction Science. 82: 13-20.

Palta, P. and Chauhan, M.S. (1998). Laboratory production of buffalo (Bubalus bubalis) embryos. Reprod. Ferti. Dev., 10:379-391.

Paramio, M. T. and Izquierdo, D. 2014. Assisted reproduction technologies in goats. Small Ruminant Research. 121(1): 21-26.

Pawshe, C. H., Totey, S. M. and Jain, S. K. 1994. A comparison of three methods of recovery of goat oocytes for In Vitro maturation and fertilization. Theriogenology. 42(1): 117-125.

Raza, A., Samad, H. A., Rehman, N. U. and Zia, E. U. H. 2001. Studies on in vitro maturation and fertilization of Nili-Ravi buffalo follicular oocytes. International Journal of Agriculture and Biology. 3(4): 503-506.

Ruhil, S. R. S. and Purohit, G. 2016. In Vitro fertilization of buffalo oocytes matured In Vitro in three different media. The Indian Journal of Animal Reproduction: 36(2).

Samad, H. A., Khan, I. Q., Rehman, N. U. and Ahmad, N. 1998. The Recovery, In Vitro Maturation and Fertilization of Nili-Ravi Buffalo Follicular Oocytes. Asian-Australasian Journal of Animal Sciences. 11(5): 491-497.
Shahid, B., Jalali, S., Khan, M. I. and Shami, S. A. 2014. Different Methods of Oocytes Recovery for In Vitro Maturation in Nili Ravi Buffalo'S Oocytes. APCBEE Procedia. 8: 359363.

Sharma, G. T. and Loganathasamy, K. 2007. Effect of meiotic stages during In Vitro maturation on the survival of vitrifiedwarmed buffalo oocytes. Veterinary research communications. 31(7): 881893.

Singh, S., Dhanda, O. P. and Malik, R. K. 2001. Effect of the Presence of Corpus Luteum on Ooctye Recovery and Subsequent In Vitro Maturation and Fertilization in Buffaloes. Asian Australasian journal of animal sciences. 14(12): 1675-1677.

Tasripoo, K. and Kamonpatana, M. 1997. Assessment of factors contributing to In Vitro maturation, fertilization and cleavage rate of swamp buffalo oocytes. Buffalo Journal. 13: 325-336.

Totey, S. M., Singh, G., Taneja, M., Pawshe, C. H. and Talwar, G. P. 1992. In Vitro maturation, fertilization and development of follicular oocytes from buffalo (Bubalus bubalis). Journal of Reproduction and Fertility. 95(2): 597607.

Verma, O. P., Kumar, R., Kumar, A. and Chand, S. 2012. Assisted reproductive techniques in farm animal-From artificial insemination to nanobiotechnology. Veterinary World 5(5): 301-310.

\section{How to cite this article:}

Kolipaka Rajesh, B. Swathi, G. Aruna Kumari and Shanmugam, M. 2018. Effect of Ovarian Status on Oocyte Quality and Recovery Rate Retrieved by Aspiration Method in Buffalo Ovaries. Int.J.Curr.Microbiol.App.Sci. 7(04): 1884-1889.

doi: https://doi.org/10.20546/ijcmas.2018.704.215 